\title{
Diabetes Mellitus and Periodontal Health: Dentists' Knowledge
}

\author{
Areej K. Al-Khabbaz Khalaf F. Al-Shammari \\ Division of Periodontics, Department of Surgical Sciences, Faculty of Dentistry, Health Sciences Center, \\ Kuwait University, Jabriya, Kuwait
}

\section{Key Words}

Diabetes mellitus $\cdot$ Periodontal diseases $\cdot$ Knowledge of dentists

\begin{abstract}
Objectives: There is a strong body of evidence to support the relationship between periodontal diseases and diabetes mellitus. Unless dental practitioners are aware of this link, they cannot apply the information to their daily practice. The aim of the study was, therefore, to evaluate the knowledge of dental practitioners concerning the effect of diabetes on periodontal health. Subjects and Methods: This was a crosssectional survey of randomly selected dental practitioners in Kuwait. Participants were asked about specific periodontal complications which they believed that patients diagnosed with diabetes were more susceptible to. Results: A total of 220 dental practitioners (133 general dental practitioners and 87 dental specialists) participated in the study. Less than $60 \%$ of all study participants reported that tooth loss due to periodontal reasons and periodontal abscess were frequent among diabetic patients. Dental specialists, especially periodontists, were significantly more aware of periodontal complications associated with diabetes. Factors significantly associated with having knowledge about the effect of dia-
\end{abstract}

betes on periodontal health in logistic regression analysis were dentists who were older and those who were specialists. Conclusions: The results of this study indicate that knowledge about the effects of diabetes on periodontal health among this sample of dental practitioners is generally low, and dentists may underestimate the outcomes of periodontal diseases in diabetic patients.

Copyright $\odot 2011$ S. Karger AG, Basel

\section{Introduction}

A bidirectional relationship exists between diabetes mellitus and periodontal diseases $[1,2]$. Patients diagnosed with diabetes are considered to be a high-risk group with greater susceptibility to severe forms of periodontal breakdown $[3,4]$. Chronic periodontitis is a common periodontal disease among adults, a potentially progressive bacterial infection that may lead to tooth loss due to extensive destruction of periodontal attachment. In addition, inflammatory response plays a major role in the progression of periodontal diseases. Controlled clinical studies have shown that subjects diagnosed with diabetes have a greater prevalence of periodontal complications compared to healthy individuals,

\section{KARGER \\ Fax +4161306 1234 \\ E-Mail karger@karger.ch}

www.karger.com
(C) 2011 S. Karger AG, Basel

1011-7571/11/0206-0538\$38.00/0

Accessible online at:

www.karger.com/mpp
Assist. Prof. Areej K. Al-Khabbaz, DDS, MS

Department of Surgical Sciences, Faculty of Dentistry, Health Sciences Center Kuwait University, Jabriya

PO Box 24923, 13110 Safat (Kuwait)

Tel. +9659929 9448, E-Mail areejalkhabbaz@hsc.edu.kw 
including gingival inflammation [5], bone resorption [6], periodontal abscess [7] and tooth loss [8]. Severe periodontitis may increase the risk of poor glycemic control $[9,10]$, and current scientific evidence supports the concept that treating periodontal infections can be influential and contribute to glycemic control management $[11,12]$. The World Health Organization advised that oral diseases, including periodontal disease, are serious health problems and considered increasing awareness of oral health worldwide should be an important component of general health and quality of life [13]. These findings indicate the importance of clinically relevant preventive and therapeutic measures for the management of both diabetes mellitus and periodontal diseases in both adults and children.

Although there is a growing body of evidence supporting the relationship between periodontal diseases and diabetes mellitus, several studies have indicated a lack of general oral health information among diabetic patients [14-17]. Most of these studies have shown that few patients diagnosed with diabetes visit the dentist on a regular basis and many are not informed of the effect of diabetes on oral health. A study by Allen et al. [15] has reported that awareness of diabetic patients about periodontal diseases is very low compared to their reported awareness of increased risk for heart disease, eye disease, kidney disease and circulatory problems. Unless dental practitioners are aware of the link between diabetes mellitus and periodontal diseases, they cannot convey this information to the patients in their practice. Few studies have evaluated dentists' attitude and behavior toward the management of patients diagnosed with diabetes [18-20]. Most of these studies have shown that few dentists monitor blood glucose levels and adjust the frequency of dental visits according to the patient's diabetic status.

As the prevalence of diabetes in Kuwait has reached almost epidemic proportions [21], it is expected that dentists are seeing and treating a large number of diabetic patients with periodontal problems. For that reason, evaluating dentists' knowledge regarding this issue will assist in making recommendations regarding the appropriate level of continuing educational programs, updating the undergraduate and postgraduate dental curriculum and initiating interprofessional collaboration between medicine and dentistry. The aim of this study was, therefore, to evaluate the knowledge of dental practitioners concerning the effect of diabetes on periodontal health.

\section{Subjects and Methods}

This was a cross-sectional survey study of randomly selected dentists practicing in the Public Health Service in Kuwait in two types of clinical settings: primary health centers and specialized dental centers. The study protocol was approved by the Ethical Review Committee of Kuwait University, Faculty of Dentistry prior to commencement of the project. Data were collected during 2008. Informed verbal consent from all participants was obtained prior to contribution. A randomized scheme was used to provide a sample size of dentists from all six districts in Kuwait. A total of 300 dentists were approached and invited to participate in the study. In addition to the major dental center serving each district, three primary polyclinics were randomly selected from each district to participate in the study. The sample was stratified to provide a representative number of general dentists and specialists practicing in the public health service in Kuwait. Participants were requested to complete an anonymous, self-administered, structured questionnaire in their clinics and return it at the end of their working hours to assure privacy. The first part of the questionnaire recorded demographic characteristics including age, gender, and years since graduation (from the last dental degree). All participants were asked to report whether they believed that diabetes affected periodontal health, and if poorly controlled diabetic patients should have more frequent dental checkups. For the above-mentioned questions participants were given the choice of 'yes', 'no', or 'I don't know'. Participants were then asked which of the following periodontal complications they believed patients diagnosed with diabetes were more susceptible to: gingival inflammation, gingival bleeding, alveolar bone resorption, tooth loss or periodontal abscess. They were asked to indicate next to each complication the one they believed to be more common among patients with diabetes than among healthy individuals.

\section{Statistical Analysis}

Data was entered and analyzed using the Statistical Package for Social Science software (SPSS, Chicago, Ill., USA), version 18. Frequency distributions and descriptive statistics were generated for all the study variables; $\chi^{2}$ test was performed to detect significant association between categorical variables. Knowledge score of 0 or 1 was used to assess knowledge level, with 1 representing adequate knowledge of possible periodontal complications associated with diabetes mellitus, and knowledge score of 0 representing inadequate knowledge of the effect of diabetes on periodontal health. The 'knowledge score' was calculated in the following manner: a score of 1 was given if the participant correctly responded to all effects of diabetes on periodontal health (gingival inflammation, gingival bleeding, tooth mobility, periodontal abscess, alveolar bone resorption and tooth loss), and the participant reported that he or she was aware that diabetes affects periodontal health and poorly controlled diabetic patients should have more frequent dental checkups; a score of 0 was given if any of these variables was not correctly answered. Binary logistic regression analysis was performed to examine which factors were significant in predicting knowledge about the effect of diabetes on periodontal health. The regression model used the dependent variable 'knowledge score'. Independent variables entered in the model were age, gender, years since graduation and dental specialty (general dentist vs. dental specialist). Statistical significance was set at $\mathrm{p}<0.05$. 
Table 1. Sociodemographic characteristics

\begin{tabular}{|c|c|c|c|c|}
\hline & $\begin{array}{l}\text { General dental } \\
\text { practitioners, n (\%) }\end{array}$ & $\begin{array}{l}\text { Dental specialists, } \\
\mathrm{n}(\%)\end{array}$ & $\begin{array}{l}\text { All participants, } \\
\mathrm{n}(\%)\end{array}$ & $\begin{array}{l}\mathrm{p} \\
\text { value }^{\mathrm{a}}\end{array}$ \\
\hline \multicolumn{5}{|l|}{ Gender } \\
\hline Male & $76(57.1)$ & $65(74.7)$ & $141(64.1)$ & \multirow{2}{*}{0.01} \\
\hline Female & $57(42.9)$ & $22(25.3)$ & $79(35.9)$ & \\
\hline \multicolumn{5}{|c|}{ Time since graduation from the last dental degree } \\
\hline$\leq 5$ years & $57(42.9)$ & $6(6.9)$ & $63(28.6)$ & \multirow{2}{*}{$<0.001$} \\
\hline$>5$ years & $76(57.1)$ & $81(93.1)$ & $157(71.4)$ & \\
\hline Mean age $\pm S D$, years & $33.7 \pm 9.1$ & $40.3 \pm 7.0$ & $36.3 \pm 8.9$ & $<0.001$ \\
\hline
\end{tabular}

Table 2. Reported periodontal complications associated with diabetes mellitus

\begin{tabular}{lllll}
\hline Periodontal complications & $\begin{array}{l}\text { General dental } \\
\text { practitioners, } \mathrm{n}(\%)\end{array}$ & $\begin{array}{l}\text { Dental specialists, } \\
\mathrm{n}(\%)\end{array}$ & $\begin{array}{l}\text { All participants, } \\
\mathrm{n}(\%)\end{array}$ & $\mathrm{p} \mathrm{value}^{\mathrm{a}}$ \\
\hline Gingival inflammation & $112(84.2)$ & $83(95.4)$ & $195(88.6)$ & 0.015 \\
Gingival bleeding & $102(76.7)$ & $73(83.9)$ & $175(79.5)$ & 0.233 \\
Periodontal abscess & $59(44.4)$ & $55(63.2)$ & $114(51.8)$ & 0.008 \\
Alveolar bone resorption & $107(80.5)$ & $83(95.4)$ & $190(86.4)$ & 0.001 \\
Tooth loss & $75(56.4)$ & $55(63.2)$ & $130(59.1)$ & 0.330 \\
\hline
\end{tabular}

$$
{ }^{\mathrm{a}} \chi^{2}(\mathrm{p}<0.05)
$$

\section{Results}

A total of 220 dentists (133 general dental practitioners and 87 dental specialists) completed the questionnaire. Dental specialists consist of 14 periodontists, 13 orthodontists, 15 prosthodontists, 8 oral surgeons, 24 endodontists and 13 pedodontists. The response rate was $73.3 \%$ (with no significant difference in response between districts). According to the annual report of the Dental Administration of the Ministry of Health in Kuwait in 2009, the total number of dentists working in $\mathrm{Ku}-$ wait in both public health and private sector during 2008 was 1,474 . The public health service consisted of 478 general dental practitioners and 243 dental specialists. Therefore our sample size represents around $28 \%$ of the general dental practitioners and $36 \%$ of the dental specialists working in the public dental health service in Kuwait.

Table 1 presents the sociodemographic characteristics of the participants. The mean age and standard deviation of general dental practitioners were 33.7 and 9.2, respec- tively. The mean age and standard deviation of dental specialists were 40.3 and 7.0, respectively. A significant difference was detected regarding the mean age between the two groups $(\mathrm{p}<0.001)$. Statistical differences were found between general dental practitioners and dental specialists in gender distribution, and in years since graduation. The above-mentioned significant difference was expected, especially since the majority of dental specialists in Kuwait are males.

Table 2 presents the reported knowledge of specific periodontal complications associated with diabetes mellitus. Around $80 \%$ of the study participants were aware that gingival inflammation, gingival bleeding and alveolar bone resorption were manifestations associated with diabetes mellitus. Only $59.1 \%$ of all study participants reported that tooth loss due to periodontal disease is frequent among diabetic patients and $51.8 \%$ of all study participants reported that periodontal abscesses were associated with diabetes. Dental specialists were significantly more aware of the association between diabetes and peri- 
Table 3. Awareness of the effects of diabetes on periodontal health

\begin{tabular}{|c|c|c|c|c|}
\hline & $\begin{array}{l}\text { General dental } \\
\text { practitioners, } \mathrm{n}(\%)\end{array}$ & $\begin{array}{l}\text { Dental specialists, } \\
\mathrm{n}(\%)\end{array}$ & $\begin{array}{l}\text { All participants, } \\
\mathrm{n}(\%)\end{array}$ & $\mathrm{p}$ value $^{\mathrm{a}}$ \\
\hline Diabetes affects periodontal health & $129(97.0)$ & $84(96.6)$ & $213(96.8)$ & 0.855 \\
\hline $\begin{array}{l}\text { Poorly controlled diabetic patients should have } \\
\text { more frequent dental checkups }\end{array}$ & $129(97.0)$ & $83(95.4)$ & $212(96.4)$ & 0.715 \\
\hline Knowledge score ${ }^{\mathrm{b}}$ & & & & \\
\hline 1 & $40(30.1)$ & $40(46.0)$ & $80(36.4)$ & \multirow{2}{*}{0.022} \\
\hline 0 & $93(69.9)$ & $47(54.0)$ & $140(63.6)$ & \\
\hline
\end{tabular}

${ }^{\mathrm{a}} \chi^{2}(\mathrm{p}<0.05)$

$\mathrm{b}$ Knowledge score: 1 ; if correctly identified gingival inflammation, gingival bleeding, periodontal abscess, alveolar bone resorption and tooth loss to be influenced by diabetes and the participant had reported that he or she was aware that diabetes affects periodontal health and poorly controlled diabetic patients should have more frequent dental checkups; a score of 0 was given if any of these variables was not correctly answered.

Table 4. Knowledge score by different dental specialty

\begin{tabular}{|c|c|c|c|c|c|c|c|c|}
\hline $\begin{array}{l}\text { Knowledge } \\
\text { score }^{\mathrm{a}}\end{array}$ & $\begin{array}{l}\text { Periodontists, } \\
\mathrm{n}(\%)\end{array}$ & $\begin{array}{l}\text { Orthodontists, } \\
\mathrm{n}(\%)\end{array}$ & $\begin{array}{l}\text { Prosthodontists, } \\
\mathrm{n}(\%)\end{array}$ & $\begin{array}{l}\text { Oral } \\
\text { surgeons, } \\
\mathrm{n}(\%)\end{array}$ & $\begin{array}{l}\text { Endodontists, } \\
\mathrm{n}(\%)\end{array}$ & $\begin{array}{l}\text { Pedodontists, } \\
\mathrm{n}(\%)\end{array}$ & $\begin{array}{l}\text { GDPs, } \\
\mathrm{n}(\%)\end{array}$ & $p$ value $^{b}$ \\
\hline
\end{tabular}

GDPs $=$ General dental practitioners.

${ }^{a}$ Knowledge score: 1 ; if correctly identified gingival inflammation, gingival bleeding, periodontal abscess, alveolar bone resorption and tooth loss to be influenced by diabetes and the participant had reported that he or she was aware that diabetes affects periodontal health and poorly controlled diabetic patients should have more frequent dental checkups; a score of 0 was given if any of these variables was not correctly answered.

${ }^{\mathrm{b}} \chi^{2}(\mathrm{p}<0.05)$.

odontal abscesses (63.4 vs. 44.4\%), and alveolar bone resorption (95.4 vs. $80.5 \%$ ), with high recorded significant differences between the two groups $(\mathrm{p}<0.008$ and $\mathrm{p}<$ 0.001 , respectively). Awareness of the effect of diabetes mellitus on periodontal health is presented in table 3 . The majority of the study participants ( $>95 \%)$ agreed that diabetes affects periodontal health and poorly controlled diabetic patients should have more frequent dental follow-ups. A significant difference was detected regarding the knowledge score between the two groups $(\mathrm{p}<0.022)$, where $46.0 \%$ of the dental specialists versus $36.0 \%$ of the general dental practitioners scored 1 on the knowledge score. Table 4 represents knowledge score by different dental specialty.

Table 5 represents binary logistic regression analysis with knowledge score as the dependent variable. Dental specialty was the most significant variable associated with knowledge level. Dental specialists $(\mathrm{OR}=1.969$; CI: $1.043-3.720 ; \mathrm{p}=0.037$ ) were significantly more likely to have adequate knowledge about the effect of diabetes on periodontal health.

\section{Discussion}

The World Dental Federation with the International Diabetes Federation have urged the need to improve the knowledge about the reciprocal link between diabetes and oral health among health professionals [22]. Increasing the knowledge of health care providers will probably improve their attitude and behavior towards the management of diabetic patients. Therefore, this study was de- 
Table 5. Logistic regression analysis of factors associated with knowledge of the effect of diabetes on periodontal health

\begin{tabular}{llll}
\hline Factor & B (SE) & OR (CI) & p value \\
\hline Age & $0.053(0.022)$ & $1.055(1.011-1.101)$ & 0.015 \\
Gender & $0.522(0.316)$ & $1.685(0.907-3.132)$ & 0.099 \\
Years since graduation & $-0.634(0.444)$ & $0.530(0.222-1.267)$ & 0.153 \\
Dental specialty & $0.678(0.324)$ & $1.969(1.043-3.720)$ & 0.037 \\
\hline
\end{tabular}

$\mathrm{OR}=$ Adjusted odds ratio; $\mathrm{CI}=95 \%$ confidence interval.

signed as one part of a cross-sectional survey that aimed to assess the knowledge of health care professionals in Kuwait about the relationship between diabetes and periodontal diseases [23]. To the best of our knowledge, this is the first study that documents dentists' knowledge of specific periodontal complications associated with diabetes mellitus in Kuwait.

The majority of respondents believed that diabetes may affect periodontal health by causing some degree of gingival inflammation and that frequent dental checkups are very important for poorly controlled diabetic patients. As we move toward more specific periodontal complications, the level of awareness decreased dramatically: only $52 \%$ of the respondents were aware that periodontal abscesses are a common manifestation of diabetes, and surprisingly, only $59 \%$ of respondents were aware that tooth loss is a common dental complication among patients diagnosed with diabetes although recent studies have documented that periodontal disease is considered to be one of the main reasons for tooth loss in diabetic individuals $[8,24,25]$. In our study, participants were unaware that severe alveolar bone resorption could take place and lead to partial or complete edentulousness. The consequences of periodontal disease and subsequent tooth loss are not only important considerations for the quality of life of patients with diabetes, but they may significantly affect general health by compromising patients' ability to continue a healthy diet and maintain good glycemic control.

Our data showed that dental specialists were significantly more aware of specific periodontal complications associated with diabetes such as gingival inflammation, alveolar bone resorption and periodontal abscess than general dental practitioners. Also, a significantly higher number of dental specialists, especially periodontists, had a knowledge score of 1 (adequate knowledge) than general dental practitioners. Because periodontists are referral-based practitioners, they are more likely to see diabetic patients with advanced periodontal disease and engage in more invasive procedures. Frequent exposure to diabetic patients with periodontal complications will prompt periodontists to communicate and interact with other health care providers, update their knowledge and maintain continuing education. A previous study has reported that only 15 of 105 general dentists (14\%) in Northeastern United States communicate often with the diabetic patients' physician and are less likely to take an active role in the management and control of diabetes [19]. General dental practitioners may feel that their role is to focus on general dental problems only and that they do not have the authority to extend the realm of their care to the management of systemic health issues.

Binary regression analysis revealed that dental specialty is the most significant predictor for having adequate knowledge about the effect of diabetes on periodontal health. After adjustment for the other predictors in the model, the estimated odds that dental specialists had knowledge of the effect of diabetes on periodontal health was 1.969 times the odds for general dental practitioners (table 5). Because older age (OR $=1.055$; CI:1.011$1.101 ; \mathrm{p}=0.015)$ participants may have more experience and exposure to diabetic patients, they may have more knowledge about the effect of diabetes on periodontal health. In addition, years since graduation were not a significant predictor for knowledge level; for former graduates ( $>5$ years), the odds of having knowledge decreased by a factor of 0.530 . Our results agree with data from Kunzel et al. [18], a study contrasting general dentists with specialists (periodontists), which reported that $70 \%$ of periodontists in the Northeastern United States compared to $49 \%$ of general dentists were good performers in terms of discussion with the patient about the association of diabetes with oral health, the importance of blood glucose control and the association of dental treatment with 
blood glucose control. The level of discussion and active management was significantly associated with the number of consultations with other dental and medical specialists. We speculate that there is a lack of interaction between general dentists and dental specialists. General dental practitioners may underestimate the need for referral to dental specialists. In a 2003 study, Bader et al. [26] investigated the ability of general dental practitioners to assess the risk factor of periodontal disease, and their results suggested a need for heightened improvement among general dentists, particularly their ability to recognize diabetes as an indicator for high risk of periodontal disease. Another survey of 160 members of the Michigan Dental Association has shown a negative attitude towards periodontal referrals among general dentists and that the more positively dentists evaluated their dental education in periodontics, the more conservative they were when considering percentage of bone loss as a basis for referral and the more frequently they used systemic antibiotics in their treatment of periodontal disease [27]. The above-mentioned results demonstrate the importance of exchanging updated scientific-based dental information among dental practitioners. General dentists are considered to be the primary referral source for patients with advanced periodontal conditions, therefore, periodontists should play a major role in educating general practitioners about the relationship between oral disease and systemic conditions.

A population-based study in the United States showed that many people were not aware that they have diabetes [28]. Their results indicate that individuals with self-reported family history of diabetes, hypertension, high cholesterol levels and clinical evidence of periodontal disease bear a probability of $27-53 \%$ of having undiagnosed diabetes. Therefore, the dental office can be the first line of defense, actively involved in screening for unidentified diabetic cases. Increasing the knowledge of dental practitioners is a very important element of early diagnosis, prevention, management and control of diabetes and periodontal disease. In our study, most dental specialists other than periodontists had inadequate knowledge about the effect of diabetes on periodontal health. Surprisingly, only $30.8 \%$ of pedodontists had an adequate knowledge about the effect of diabetes on periodontal health. This percentage is considered to be very low compared to the prevalence of diabetes among children in Kuwait $[21,29]$. Recent studies have shown that accelerated periodontal destruction in children with diabetes is related to poor metabolic control since periodontal destruction can start very early in life and becomes more prominent as diabetic children become adolescents [5]. Consequently, it is vital that pedodontists and other dental specialists be aware of the effect of diabetes on periodontal health to identify diabetic children with poor metabolic control, aid in screening of undiagnosed diabetic cases, and provide the appropriate dental treatment.

Professional attention should be given to the importance of the relationship between oral health and systemic health. It is very essential for both general dental practitioners and dental specialists to understand the relationship between diabetes mellitus and periodontal diseases. Conducting educational programs and encouraging exchange of knowledge between dental practitioners, dental specialists and medical profession are extremely important to effectively prevent, manage and control both diabetes and periodontal diseases. Periodontists should play a major role in educating general dental practitioners about the risk of developing periodontal disease in patients diagnosed with diabetes and the potential for patients with existing severe periodontal disease of being diabetic. In addition, the undergraduate and postgraduate dental curriculum should put great emphasis on the interprofessional education between medicine and dentistry.

\section{Conclusion}

Within the limitations of the present study, which relies upon self-reported data, knowledge of specific periodontal complications associated with diabetes among this sample was generally low. There may be an underestimation of the extent, severity and the outcomes of periodontal diseases in patients diagnosed with diabetes by dental practitioners.

\section{Acknowledgment}

This study was supported by Kuwait University research grant No. ZD 02/07. 


\section{References}

$>1$ Taylor GW: Bidirectional interrelationships between diabetes and periodontal diseases: an epidemiologic perspective. Ann Periodontol 2001;6:99-112.

$>2$ Mealey BL, Oates TW: Diabetes mellitus and periodontal diseases. J Periodontol 2006;77: 1289-1303.

3 Johnson NW, Griffiths GS, Wilton JM, Maiden MF, Curtis MA, Gillett IR, Wilson DT, Sterne JA: Detection of high-risk groups and individuals for periodontal diseases: evidence for the existence of high-risk groups and individuals and approaches to their detection. J Clin Periodontol 1988;15:276-282.

4 Grossi SG, Zambon JJ, Ho AW, Koch G, Dunford RG, Machtei EE, Norderyd OM, Genco RJ: Assessment of risk for periodontal disease. I. Risk indicators for attachment loss. J Periodontol 1994;65:260-267.

$>5$ Lalla E, Cheng B, Lal S, Tucker S, Greenberg E, Goland R, Lamster IB: Periodontal changes in children and adolescents with diabetes: a case-control study. Diabetes Care 2006;29: 295-299.

-6 Tervonen T, Karjalainen K, Knuuttila M, Huumonen S: Alveolar bone loss in type 1 diabetic subjects. J Clin Periodontol 2000;27: 567-571.

$>7$ Ueta E, Osaki T, Yoneda K, Yamamoto T: Prevalence of diabetes mellitus in odontogenic infections and oral candidiasis: an analysis of neutrophil suppression. J Oral Pathol Med 1993;22:168-174.

-8 Kaur G, Holtfreter B, Rathmann W, Schwahn C, Wallaschofski H, Schipf S, Nauck M, Kocher T: Association between type 1 and type 2 diabetes with periodontal disease and tooth loss. J Clin Periodontol 2009;36:765774 .

9 Taylor GW, Burt BA, Becker MP, Genco RJ, Shlossman M, Knowler WC, Pettitt DJ: Severe periodontitis and risk for poor glycemic control in patients with non-insulin-dependent diabetes mellitus. J Periodontol 1996; 67:1085-1093.
10 Collin HL, Uusitupa M, Niskanen L, Kontturi-Narhi V, Markkanen H, Koivisto AM, Meurman JH: Periodontal findings in elderly patients with non-insulin dependent diabetes mellitus. J Periodontol 1998;69:962966.

11 Kiran M, Arpak N, Unsal E, Erdogan MF: The effect of improved periodontal health on metabolic control in type 2 diabetes mellitus. J Clin Periodontol 2005;32:266-272.

12 Jones JA, Miller DR, Wehler CJ, Rich SE, Krall-Kaye EA, McCoy LC, Christiansen CL, Rothendler JA, Garcia RI: Does periodontal care improve glycemic control? The department of veterans affairs dental diabetes study. J Clin Periodontol 2007;34:46-52.

13 Petersen PE: Global policy for improvement of oral health in the 21st century: implications to oral health research of World Health Assembly 2007, World Health Organization. Community Dent Oral Epidemiol 2009;37: $1-8$.

14 Jansson H, Lindholm E, Lindh C, Groop L, Bratthall G: Type 2 diabetes and risk for periodontal disease: a role for dental health awareness. J Clin Periodontol 2006;33:408414.

15 Allen EM, Ziada HM, O’Halloran D, Clerehugh V, Allen PF: Attitudes, awareness and oral health-related quality of life in patients with diabetes. J Oral Rehabil 2008;35:218223.

-16 Al Habashneh R, Khader Y, Hammad MM, Almuradi M: Knowledge and awareness about diabetes and periodontal health among Jordanians. J Diabetes Complications 2010;24:409-414.

17 Dental visits among dentate adults with diabetes: United States, 1999 and 2004. MMWR Morb Mortal Wkly Rep 2005;54:1181-1183.

18 Kunzel C, Lalla E, Lamster I: Dentists' management of the diabetic patient: contrasting generalists and specialists. Am J Public Health 2007;97:725-730.

19 Kunzel C, Lalla E, Lamster IB: Management of the patient who smokes and the diabetic patient in the dental office. J Periodontol 2006;77:331-340.
20 Forbes K, Thomson WM, Kunzel C, Lalla E, Lamster IB: Management of patients with diabetes by general dentists in New Zealand. J Periodontol 2008;79:1401-1408.

-21 Moussa MA, Alsaeid M, Abdella N, Refai TM, Al-Sheikh N, Gomez JE: Prevalence of type 2 diabetes mellitus among Kuwaiti children and adolescents. Med Princ Pract 2008; 17:270-275.

22 The International Dental Federation: Oral Health and Diabetes Symposium. 2007; available at: http://www.idf.org/guidelines/ diabetes-and-oral-health.

23 Al-Khabbaz AK, Al-Shammari KF, Al-Saleh NA: Knowledge about the association between periodontal diseases and diabetes mellitus: contrasting dentists and physicians. J Periodontol 2011;82:360-366.

24 Al-Shammari KF, Al-Khabbaz AK, Al-Ansari JM, Neiva R, Wang HL: Risk indicators for tooth loss due to periodontal disease. J Periodontol 2005;76:1910-1918.

25 Kapp JM, Boren SA, Yun S, LeMaster J: Diabetes and tooth loss in a national sample of dentate adults reporting annual dental visits. Prev Chronic Dis 2007;4:A59.

-26 Bader JD, Shugars DA, Kennedy JE, Hayden WJ Jr, Baker S: A pilot study of risk-based prevention in private practice. J Am Dent Assoc 2003;134:1195-1202.

27 Lee JH, Bennett DE, Richards PS, Inglehart MR: Periodontal referral patterns of general dentists: lessons for dental education. J Dent Educ 2009;73:199-210.

28 Borrell LN, Kunzel C, Lamster I, Lalla E: Diabetes in the dental office: using NHANES III to estimate the probability of undiagnosed disease. J Periodontal Res 2007;42: 559-565.

29 Moussa MA, Alsaeid M, Abdella N, Refai TM, Al-Sheikh N, Gomez JE: Prevalence of type 1 diabetes among 6- to 18 -year-old $\mathrm{Ku}$ waiti children. Med Princ Pract 2005;14:8791. 